\title{
Effect of Crystallographic Orientation and Grain Boundaries on Martensitic Transformation and Superelastic Response of Oligocrystalline Fe-Mn-Al-Ni Shape Memory Alloys
}

\author{
A. Bauer ${ }^{1} \cdot$ M. Vollmer $^{1} \cdot$ T. Niendorf $^{1}$ (D
}

Received: 1 May 2021/Revised: 1 July 2021 / Accepted: 4 July 2021 / Published online: 26 July 2021

(C) The Author(s) 2021

\begin{abstract}
In situ tensile tests employing digital image correlation were conducted to study the martensitic transformation of oligocrystalline $\mathrm{Fe}-\mathrm{Mn}-\mathrm{Al}-\mathrm{Ni}$ shape memory alloys in depth. The influence of different grain orientations, i.e., near- $\langle 001\rangle$ and near- $\langle 101\rangle$, as well as the influence of different grain boundary misorientations are in focus of the present work. The results reveal that the reversibility of the martensite strongly depends on the type of martensitic evolving, i.e., twinned or detwinned. Furthermore, it is shown that grain boundaries lead to stress concentrations and, thus, to formation of unfavored martensite variants. Moreover, some martensite plates seem to penetrate the grain boundaries resulting in a high degree of irreversibility in this area. However, after a stable microstructural configuration is established in direct vicinity of the grain boundary, the transformation begins inside the neighboring grains eventually leading to a sequential transformation of all grains involved.
\end{abstract}

Keywords FeMnAlNi - Shape memory alloys ·

Oligocrystalline structure $\cdot$ Martensitic phase transformation - Crystallographic orientation - Digital image correlation - Grain boundaries

This article is part of a special topical focus in Shape Memory and Superelasticity on Fe-Based Shape Memory Alloys. This issue was organized by Dr. Toshihiro Omori and Dr. Ryosuke Kainuma, Tohoku University.

M. Vollmer

vollmer@uni-kassel.de

$\triangle$ T. Niendorf

niendorf@uni-kassel.de

1 Institute of Materials Engineering, Universität Kassel, 34125 Kassel, Germany

\section{Introduction}

Shape memory alloys (SMAs) are able to show large recoverable strains due to a fully reversible thermo-elastic phase transformation [1]. Enabled by extensive research activities in the last decades, $\mathrm{Ni}-\mathrm{Ti}$ became the most commonly used SMA in various industrial applications. It is characterized by superior shape memory and superelastic properties combined with good functional fatigue resistance and good biocompatibility [2]. However, most of the applications so far focus on small-sized components in biomedical, aerospace, automotive and the robotics domain. This is due to the fact that alloying elements are cost intensive and machinability is very challenging [2, 3]. In order to overcome these limitations, low-cost iron-based SMAs with superior machinability gained increased attention in recent years [4-8]. One of the most promising alloy systems is $\mathrm{Fe}-\mathrm{Mn}-\mathrm{Al}-\mathrm{Ni}-\mathrm{X}(X=\mathrm{Ti}, \mathrm{Cr})$ [9-12]. For this alloy system superelastic strains up to $5 \%$ in polycrystals [11] and up to $10 \%$ in single crystals [11, 13] have been reported. Additionally, $\mathrm{Fe}-\mathrm{Mn}-\mathrm{Al}-\mathrm{Ni}$ is characterized by a low temperature dependence of the critical stress for martensitic transformation (0.53 MPa K-1) [11] making it attractive for large scale damping applications in numerous fields.

Essential for the fully reversible phase transformation in this system is the formation of nano-sized, ordered and coherent $\beta$ precipitates $(\mathrm{B} 2-\mathrm{bcc} / \mathrm{NiAl})$ in the disordered $\alpha$ matrix (A2-bcc) leading to a change from non-thermoelastic to thermo-elastic behavior [11, 14]. Omori et al. [14] reported that the $\beta$ precipitates are elastically distorted during the martensitic transformation retaining their coherency even in the martensitic $\gamma^{\prime}$ phase (A1-fcc). In contrast to the precipitate-free and non-thermo-elastic $\mathrm{Fe}-$ $\mathrm{Mn}-\mathrm{Al}$ alloy [15], nano-twins were found in the 
martensitic phase in the vicinity of the precipitates and it was assumed that the interaction between the precipitates and martensite is a key factor for the thermo-elastic character of the phase transformation in this SMA [14]. To promote an optimum balance of properties taking into account precipitate induced hardening and coherency between precipitates and matrix, a precipitate size of 6-10 nm was adjusted via heat treatment at $200{ }^{\circ} \mathrm{C}$ for $3 \mathrm{~h}$ [16]. However, in light of its susceptibility to room-temperature aging [17] precipitate sizes of about $13 \mathrm{~nm}$ were stated to be more appropriate to ensure good superelastic properties and microstructure stability at RT for this SMA [18].

In addition to precipitates, the crystallographic grain orientation has a significant influence on the superelastic properties. The relation between the bcc $\alpha$ matrix (austenite) and the fcc $\gamma^{\prime}$ martensite can be described based on the Kurdjumov-Sachs relationship [19]. If stress is applied, martensite variants characterized by high resolved shear stresses in the particular grain orientation are favored compared to the variants with low resolved shear stresses. By applying the energy minimization theory [20] (for twinned martensite) and the lattice deformation theory [21] (for detwinned martensite) taking into account the experimentally determined lattice parameters of the $\alpha$ phase $(0.2903 \mathrm{~nm})$ and $\gamma^{\prime}$ phase $(0.3672 \mathrm{~nm})$ [11], theoretical transformation strains were calculated in several studies [11, 22-26]. In tension, a high anisotropy of the calculated transformation strains between $10.5 \%$ ( $\langle 001\rangle$ orientation) and $3 \%(\langle 111\rangle$ orientation) for twinned martensite [22] and between $26.5 \%(\langle 001\rangle$ orientation) and 3.3\% ( $\langle 111\rangle$ orientation) for detwinned martensite [11] was revealed [22]. However, despite of the high transformation strains, Tseng et al. [22] reported on limited reversibility of the martensitic transformation starting at $4 \%$ total strain in a $\langle 001\rangle$ oriented single crystalline sample (aged at $200{ }^{\circ} \mathrm{C}, 3 \mathrm{~h}$ ), whereas a $\langle 123\rangle$-oriented single crystal (aged at $200{ }^{\circ} \mathrm{C}$, $3 \mathrm{~h}$ ) showed a perfect reversibility under tension up to failure at $9 \%$ total strain. Based on complementary transmission electron microscopy (TEM) analysis focusing on a $\langle 001\rangle$-oriented single crystal aged at $200{ }^{\circ} \mathrm{C}$ for $15 \mathrm{~min}$, which was initially strained up to $8 \%$, and on a non-aged $\langle 123\rangle$-oriented single crystal, which was initially loaded up to $4 \%$ strain, further insights into underlying elementary mechanisms were provided. It was concluded that only a single (detwinned) martensite variant, which is not able to accommodate the strain without plastic deformation, transforms in $\langle 001\rangle$ orientation, whereas evolution of twinned martensite leads to a sufficient level of strain accommodation in $\langle 123\rangle$ orientation and, thus, to superior superelastic properties. However, up to now the basic mechanism leading to a reversibility loss after $4 \%$ applied strain is not clearly understood. In order to close this gap, in situ experiments were carried out in present work (considering the calculated theoretical strains provided in literature in parallel) to shed light on the local transformation behavior during superelastic loading in different orientations.

Moreover, up to now, the majority of studies focused on single crystalline $[12,13,16,19,22-24,26,27]$ and oligocrystalline states [11, 28-30], since the superelastic performance of $\mathrm{Fe}-\mathrm{Mn}-\mathrm{Al}-\mathrm{Ni}$ SMAs is significantly influenced by the relative grain size with respect to the cross section of the samples [31]. In particular, in polycrystalline state the large transformation anisotropy of the alloy leads to pronounced incompatibilities at the grain boundaries. Especially in the vicinity of triple junctions, this incompatibilities lead to stress concentrations, which are thought to be responsible for a detrimental superelastic behavior [32] and for the initiation of intergranular fracture [29]. Similar observations have also been made in $\mathrm{Cu}$ based SMAs [33-38] and Co-based SMAs [39, 40]. Moreover, it was shown that the superelastic performance significantly can be improved in an oligocrystalline state, i.e., in case the mean grain size exceeds the cross section of the samples [11, 31, 41]. In Fe-Mn-Al-Ni such coarse grain structures can be obtained by abnormal grain growth (AGG) stimulated by a cyclic heat treatment between the $\alpha$ single-phase region and the $\alpha+\gamma$ two-phase region $[11,42]$. Despite the possibility to produce large single crystals by AGG [10, 42], oligocrystalline structures seem to be more appropriate in the light of industrial applications. This is due to lower restrictions regarding the component size and the more robust producibility. However, up to now the interaction between local martensitic transformation and grain boundaries is not well understood in oligocrystalline $\mathrm{Fe}-\mathrm{Mn}-\mathrm{Al}-\mathrm{Ni}$ [32].

In the present study, high resolution in situ tensile tests supported by digital image correlation (DIC) were conducted to investigate the influence of individual grain orientations and of grain boundaries on the martensitic transformation in oligocrystalline structures. For this purpose, oligocrystalline samples characterized by different orientations and different misorientation angles between the grains involved in the transformation were studied. The correlation between the theoretical transformation strains and the experimentally determined local strains is exploited to provide for novel insights into the evolution of martensite during loading and further shed light on the reverse transformation during unloading. 


\section{Material and Methods}

$\mathrm{Fe}-\mathrm{Mn}-\mathrm{Al}-\mathrm{Ni}$ ingots with a nominal chemical composition of $\mathrm{Fe}-34 \% \mathrm{Mn}-15 \% \mathrm{Al}-7.5 \% \mathrm{Ni}$ (at.\%) were produced by vacuum induction melting. Dog-bone-shaped tensile samples with a gauge length of $12 \mathrm{~mm}$ and a cross section of $1.6 \mathrm{~mm} \times 1.5 \mathrm{~mm}$ were extracted by electro-discharge machining (EDM). The samples were then ground to a grit size of $5 \mu \mathrm{m}$ and sealed into quartz tubes under argon atmosphere. A cyclic heat treatment between the $\alpha$ singlephase region $\left(1200{ }^{\circ} \mathrm{C}\right)$ and the $(\alpha+\gamma)$ two-phase region $\left(900{ }^{\circ} \mathrm{C}\right)$ was carried out to promote AGG. Three heat treatment cycles were conducted, each with a dwell time of $30 \mathrm{~min}$ at $1200{ }^{\circ} \mathrm{C}$ and $15 \mathrm{~min}$ at $900{ }^{\circ} \mathrm{C}$. The heating and cooling ramps were $10 \mathrm{~K} / \mathrm{min}$. After the final heat treatment cycle the samples were hold for $60 \mathrm{~min}$ at $1200{ }^{\circ} \mathrm{C}$ and then quenched into $80^{\circ} \mathrm{C}$ warm water to suppress cracking and martensite formation during quenching $[29,43]$. Finally, the samples were aged at $200{ }^{\circ} \mathrm{C}$ for $3 \mathrm{~h}$ to introduce well-dispersed nano-sized $\beta$ precipitates. For the following microstructural analysis and tests the samples were again ground to $5 \mu \mathrm{m}$ and then vibration-polished using a colloidal $\mathrm{SiO}_{2}$ suspension with $0.02 \mu \mathrm{m}$ particle size. For microstructural characterization, a scanning electron microscope (SEM) operating at $20 \mathrm{kV}$ equipped with an electron-backscatter diffraction (EBSD) system was used.

The experimental setup for the in situ tensile tests comprised a miniature load frame (Kammrath \& Weiss, Germany) and a confocal laser scanning microscope (CLSM) type LEXT OLS3100 (Olympus, Japan). The tensile tests were performed with a constant crosshead displacement rate of $1.2 \mu \mathrm{m} \mathrm{s}^{-1}$ under displacement control. Strain values for the stress-strain diagrams were calculated from displacement data. The use of the CLSM allowed for taking high resolution images (with high depth of focus) of the sample surface during the tensile test. During CLSM image acquisition, the tensile test was stopped at defined positions and the displacement was kept constant. For the CLSM overview images of the sample surfaces in present work, several images were merged using Photoshop CS6 (Adobe, USA). The high resolution of the detail images and the natural grayscale contrast of the polished surfaces enabled the subsequent calculation of local strains using digital image correlation (DIC). For this purpose, images of the samples in the initial state were correlated with images in the deformed states using the software VIC-2D (Correlated Solutions Inc., USA). For each analysis parameters for DIC, such as subset and step size, have been individually chosen to allow for robust correlation. By direct comparison of the experimentally determined strains in load direction (LD) with the theoretical transformation strains of the respective grain orientation [22] according to the energy minimization theory [20] and the lattice deformation theory [21], respectively, conclusions could be drawn assessing the martensite structure being locally present, i.e., twinned or detwinned.

\section{Results and Discussion}

To study the influence of different grain orientations, in situ tensile tests on oligocrystalline samples were conducted (Fig. 1). In the first sample the transformation takes place in a near- $\langle 101\rangle$-oriented grain (Fig. 1a), whereas in the second sample the martensite initially transforms in the right, i.e., the near- $\langle 001\rangle$-oriented grain (Fig. 1c). In the following, the samples are referred to as the "near- $\langle 101\rangle$ sample" and the "near- $\langle 001\rangle$ sample", respectively. The corresponding stress-strain curves reveal the superelastic behavior of both samples (Fig. 1b and Fig. 1d). Due to different resolved shear stress factors $(0.36$ for the $\langle 101\rangle$ orientation and 0.44 for the $\langle 001\rangle$ orientation [44]) the critical stress for martensitic transformation $\sigma_{\text {crit }}^{\mathrm{Ms}}$ is higher in the near $\langle 101\rangle$ sample (Fig. 1b) as compared to the critical stress of the near- $\langle 001\rangle$ sample (Fig. 1d). It is obvious, that the near- $\langle 101\rangle$ sample shows excellent reversibility after loading up to $7 \%$ strain. Interestingly, the near- $\langle 001\rangle$ sample reveals partial reversibility of more than $4 \%$, which was not the case in incremental strain tests on $\langle 001\rangle$-oriented single crystals conducted by Tseng et al. [22].

CLSM overview images of the near- $\langle 101\rangle$ sample in the loaded condition at $7 \%$ strain and after unloading are shown in Fig. 2a and b, respectively. In good agreement with the stress-strain curves, the apparent topography,

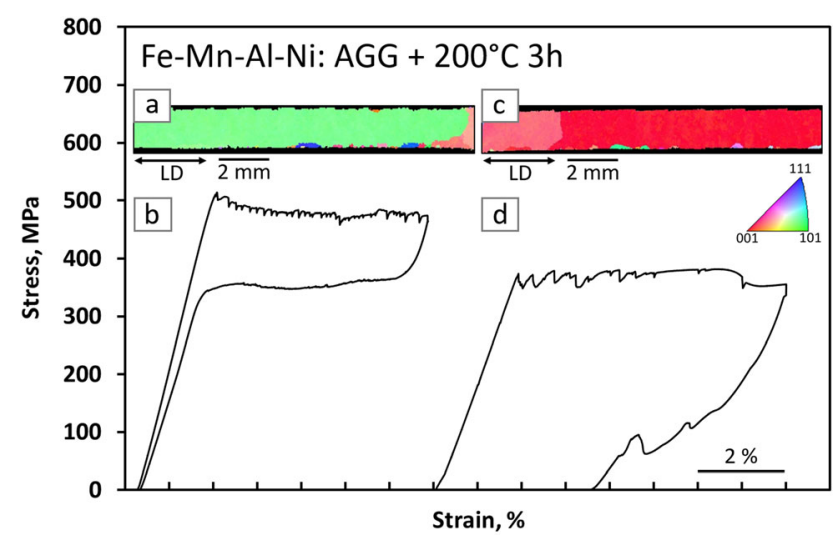

Fig. 1 Superelastic behavior of Fe-Mn-Al-Ni tensile samples with different grain orientations. EBSD orientation map plotted for LD of the near- $\langle 101\rangle$ sample (a) and the corresponding stress-strain curve up to $7 \%$ applied strain (b), EBSD orientation map plotted for LD of the near- $\langle 001\rangle$ sample (c) and the corresponding stress-strain curve up to $8 \%$ applied strain (d) 


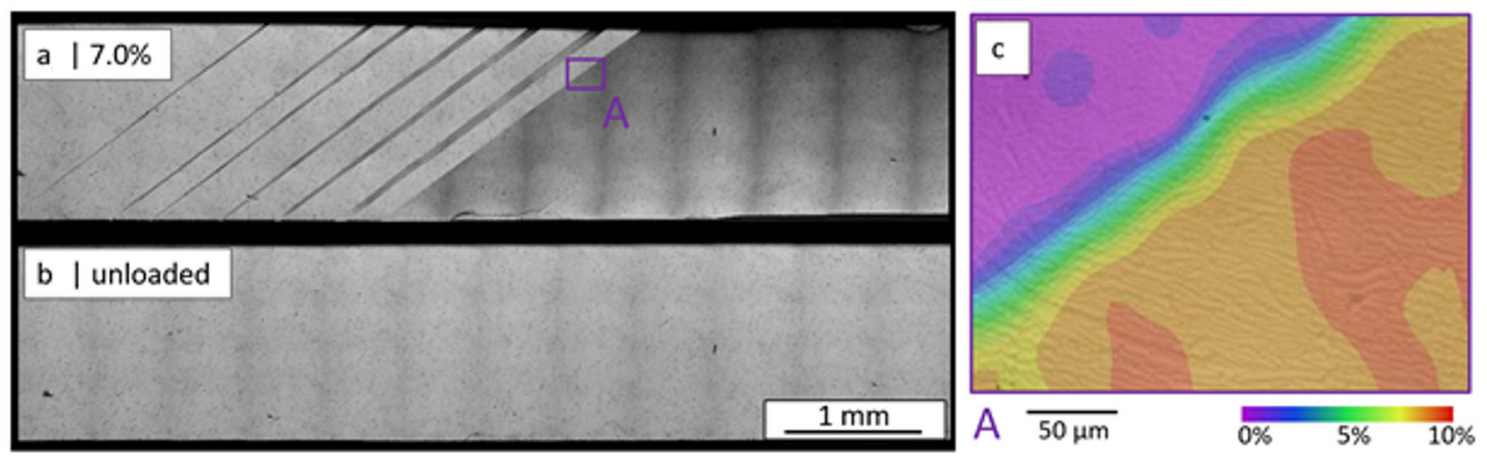

Fig. 2 In situ characterization of the near- $\langle 101\rangle$ sample shown in Fig. 1a and b. CLSM overview image of the sample in the loaded (a) and unloaded (b) condition, and the local strain distribution in LD of the area marked with A determined via DIC (c)

which can be linked to the martensitic transformation (Fig. 2a), vanishes after unloading (Fig. 2b). Evaluating the image in the loaded state, it becomes obvious that only martensite plates of one orientation evolved within the grain eventually leading to a uniform transformation front. In order to investigate in how far these martensite plates consist of twinned or detwinned martensite, DIC was applied within the highlighted area marked with $\mathrm{A}$ in Fig. 2a. Figure $2 c$ shows the local strain distribution in LD. It is obvious that the strain is mainly accommodated by the martensite, whereas the austenite is only elastically deformed. The maximum strain determined by DIC in the martensite is $9.2 \%$. For assessment of the prevailing martensite (i.e., twinned or detwinned martensite), the maximum strain in martensite is compared with the calculated theoretical transformation strains of this orientation. Theoretical values are about $9 \%$ for a twinned structure and about $13 \%$ for a detwinned structure [22]. Apparently, the strain accommodated by the martensite plates is almost the same as the theoretical transformation strain of the twinned martensite structure. Despite other effects influencing the local strain measurement, such as elastic strain, potential plastic deformation and/or topography changes upon transformation (only 2D surface data are evaluated), it can be still concluded that a twinned martensite structure is formed in this orientation. This kind of martensite eventually promotes excellent reversibility of transformation.

Figure 3a shows the CLSM overview image of the near$\langle 001\rangle$ sample (shown in Fig. 1c and d) at 5\% applied strain. Many differently oriented martensite plates are formed, leading to obvious topography changes. With increasing load up to $8 \%$ strain (Fig. 3b), a visually uniform region characterized by significant necking is formed around the area marked with $\mathrm{B}$. In this area it is no longer possible to distinguish between individual martensite plates. After unloading (Fig. 3c), a high degree of irreversibility prevails in the necked area, whereas individual martensite plates outside of the necked area (marked with A in Fig. 3b) transform back after unloading. The partial reversibility of individual regions is in good agreement with the stressstrain curve shown in Fig. 1d, which shows partial reversibility of the applied strain. For a more detailed analysis, the local strains in the areas marked with A and B in Fig. 3b were assessed by DIC (shown in Fig. 3d, e, respectively). While the maximum strain seen in case of the reversible martensite in area $\mathrm{A}$ is around $11.4 \%$, the maximum strain found for the irreversible martensite in area B is significantly higher, i.e., around $23.3 \%$. A direct comparison of the experimentally determined values with the theoretical transformation strains for this orientation clearly indicates that the strain in the reversible area A well corresponds to the theoretical transformation strain of the twinned martensite (10.5-11\% [22]), whereas the strain in case of the irreversible area B approximately corresponds to the theoretical transformation strain of the detwinned martensite (26.5\% [11]). Therefore, it can be concluded that the initially transformed areas consist of twinned martensite, which then detwin under progressive loading accompanied by obvious necking. In the further course of loading, new twinned martensite transforms outside the necked area, which again detwins under proceeding loading. After unloading, the twinned martensite shows good reversibility, whereas the transformation within the detwinned area is almost completely irreversible. The results are in good agreement with the results of Tseng et al. $[22,23]$, who revealed a strong dependence of the reversibility on the formation of twinned or detwinned martensite in single crystals. They showed that the strain accommodation at the phase boundary between a detwinned martensite variant and the austenite is accompanied by severe formation of dislocations imposed by the high lattice misfit, eventually impairing reversibility during unloading.

In a study focusing on the functional fatigue mechanisms of $\langle 001\rangle$ oriented $\mathrm{Fe}-\mathrm{Mn}-\mathrm{Al}-\mathrm{Ni}$ single crystals 


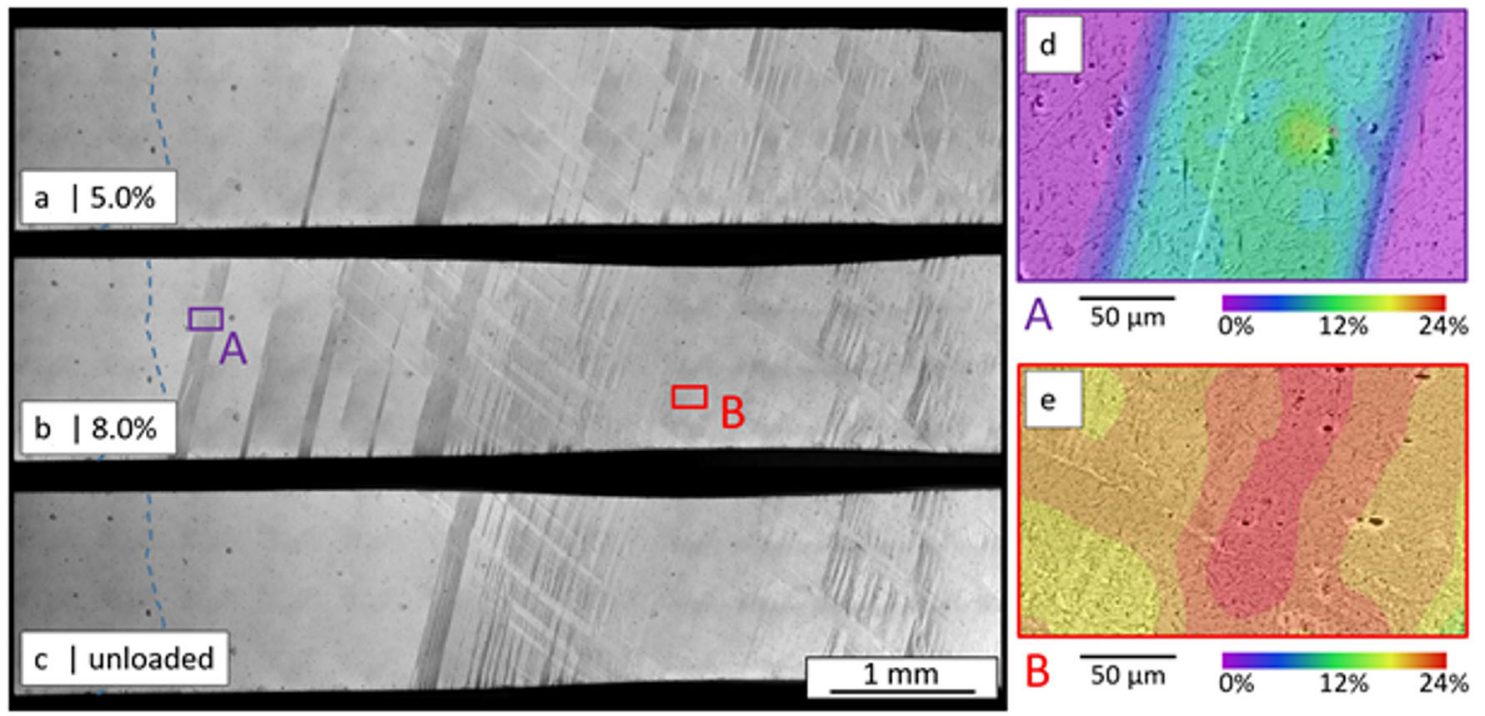

Fig. 3 In situ characterization of the near- $\langle 001\rangle$ sample shown in Fig. 1c and d. CLSM overview images of the sample at 5\% applied strain (a), 8\% applied strain (b) and after unloading (c). The blue

loaded up to $3.5 \%$ in tension [19], a progressive activation of new areas of the sample during cyclic loading was observed. Areas with newly transformed martensite were characterized by good reversibility upon subsequent unloading, however, hampered reactivation of martensite after further cycling $[19,30]$. In the light of the results presented here, it can be assumed that the stress induced martensite is initially twinned, however, later on detwins with further loading eventually leading to necking and high degrees of irreversibility. Based on the elementary mechanisms resolved here, it seems to be feasible to increase the reversibility of specific orientations tending to detwin. In such cases, the energetic barrier for detwinning has to be increased in comparison to the energetic barrier for the transformation of new areas.

To investigate the transformation behavior at grain boundaries of oligocrystalline structures, in situ tensile tests were performed on two $\mathrm{Fe}-\mathrm{Mn}-\mathrm{Al}-\mathrm{Ni}$ samples characterized by different misorientations between the involved grains. Figure 4 shows the EBSD orientation map (a), the corresponding $\langle 001\rangle$ pole figure of the grains involved in the transformation (b), as well as the stressstrain curve up to a total strain of $18 \%$ (c) of the near- $\langle 001\rangle$ sample already considered before. The grain boundary between the two near- $\langle 001\rangle$ oriented grains is characterized by a misorientation angle of $23^{\circ}$.

After reloading a stress plateau at the same level as before can be seen. Only minor reversibility of the transformation can be made out after unloading at $18 \%$ strain. Figure 5a shows a CLSM overview image of the area highlighted in Fig. 4a in the loaded condition at 18\% strain. Within the area of the grain boundary marked by the dotted lines indicate grain boundaries. The local strain distributions in LD of the areas marked in (b) with A and B are shown in (d) and (e) (Color figure online)

dashed blue line it can be seen that martensite plates cross the grain boundary with almost no change in orientation. This is different to observations made by Ueland and Schuh $[34,35]$ in a Cu-based SMA. They showed that grain boundaries have an influence on the orientation of activated martensite plates, however, no martensite crossing the grain boundaries has been revealed. In the present case, both grains (austenite) have a similar orientation and, thus, a similar orientation of the martensite is favorable in both grains.

A kind of locally stable condition is established after the martensite plates crossed the grain boundary (i.e., no further changes are seen in this area) and the transformation proceeds inside the grain as it is highlighted by the martensite plate marked with a black arrow in the interior of the left grain. After unloading (Fig. 5b), the area marked with the black arrow reveals a fully reversible transformation, whereas in the area of the grain boundary, a major amount of martensite remains in both, the firstly and the subsequently transformed grain. By direct comparison of the in situ observations with the stress-strain curve shown in Fig. 4c it becomes obvious that the sudden transformation of the martensite plate within the secondly activated grain can be correlated to the stress drop just before the end of the loading plateau. Furthermore, the reverse transformation during unloading leads to a small plateau at about $240 \mathrm{MPa}$.

In Fig. 6a, the grain boundary area, marked in Fig. 5a, is shown in detail. Most of the martensite plates cross the grain boundary without a change of orientation. However, additional martensite plates with deviating orientations (red arrows in Fig. 6a) indicate that locally differing stress 
Fig. 4 Superelastic behavior of the $\mathrm{Fe}-\mathrm{Mn}-\mathrm{Al}-\mathrm{Ni}$ tensile sample being characterized by a misorientation angle of $23^{\circ}$ between the transforming grains. EBSD orientation mapping plotted for LD (a) of the sample already shown in Fig. 1 (c) and (d). The area considered for in situ characterization is marked with a white box. The corresponding $\langle 001\rangle$ pole figure highlighting the orientation of the transforming grains is shown in (b) besides the stress-strain curve up to $18 \%$ applied strain in $(\mathbf{c})$

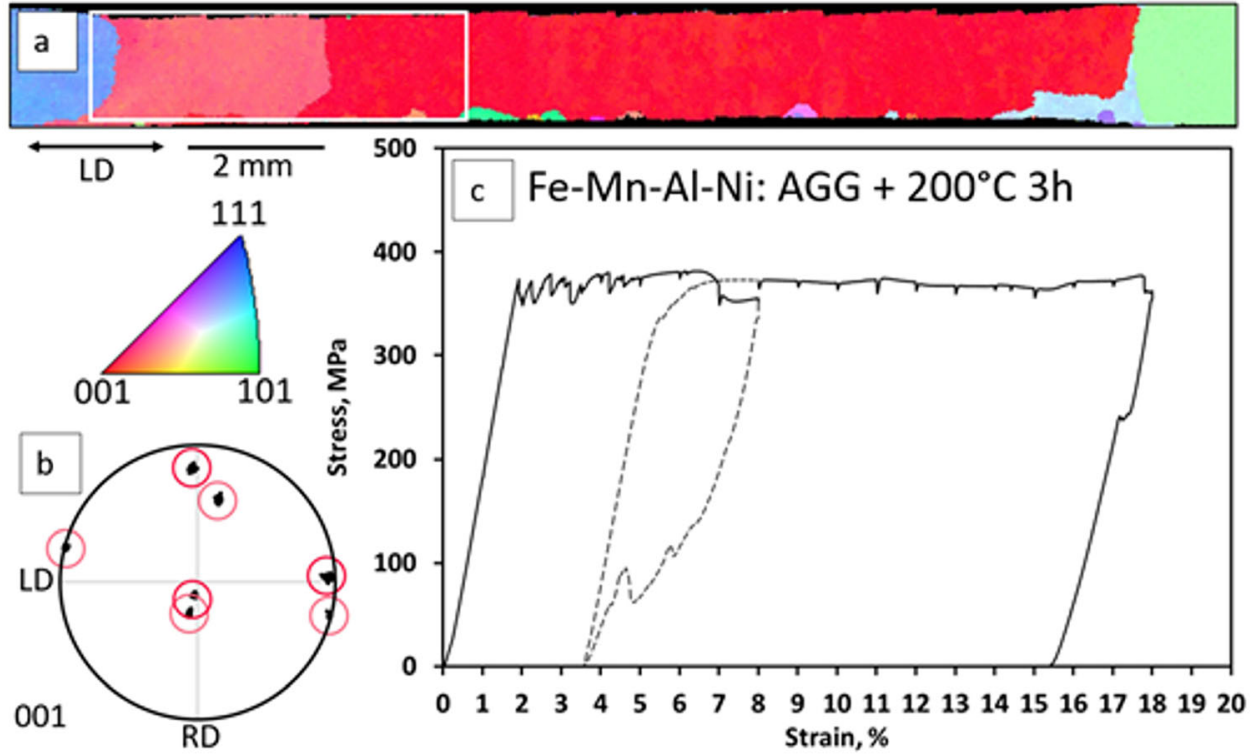

a robust correlation within this very narrow area based on the DIC parameters chosen, it is concluded that additional martensite plates were formed due to stress concentrations in the vicinity of the grain boundary. Obviously, these variants do not have a favored orientation with respect to strain accommodation in LD. Evaluation of the unloaded state reveals that the martensite plates are not reversible at this spot. Based on these results, it is likely that despite of the low misorientation between the grains, high stress concentrations are present during loading, which lead to high dislocation densities and to the formation of unfavorable martensite eventually resulting in a high degree of irreversibility in the vicinity of the grain boundary. In a former study it was shown that even subgrains with a misorientation of about $3^{\circ}$ can be detrimental for the superelastic performance in $\mathrm{Fe}-\mathrm{Mn}-\mathrm{Al}-\mathrm{Ni}-\mathrm{Ti}$ [10]. Compared to a sample without subgrains, a higher critical stress for martensitic transformation, a larger stress hysteresis and eventually a lower recoverability were observed. It was shown that the martensite crosses the subgrain structures, however, in some subgrains additional martensite variants occurred. Detailed investigations of the influence of subgrains on the martensitic transformation have not yet been carried out and will be considered in more depth in future studies.

Figure 7 shows an EBSD orientation map (a), the corresponding $\langle 001\rangle$ pole figure of the grains involved in the transformation (b) and the stress-strain curve up to a maximum load of $5.5 \%$ strain (c) of a different oligocrystalline tensile sample. The grain boundary considered here is highlighted by a white box in Fig. 7a and has a misorientation angle of $60^{\circ}$. In contrast to the 

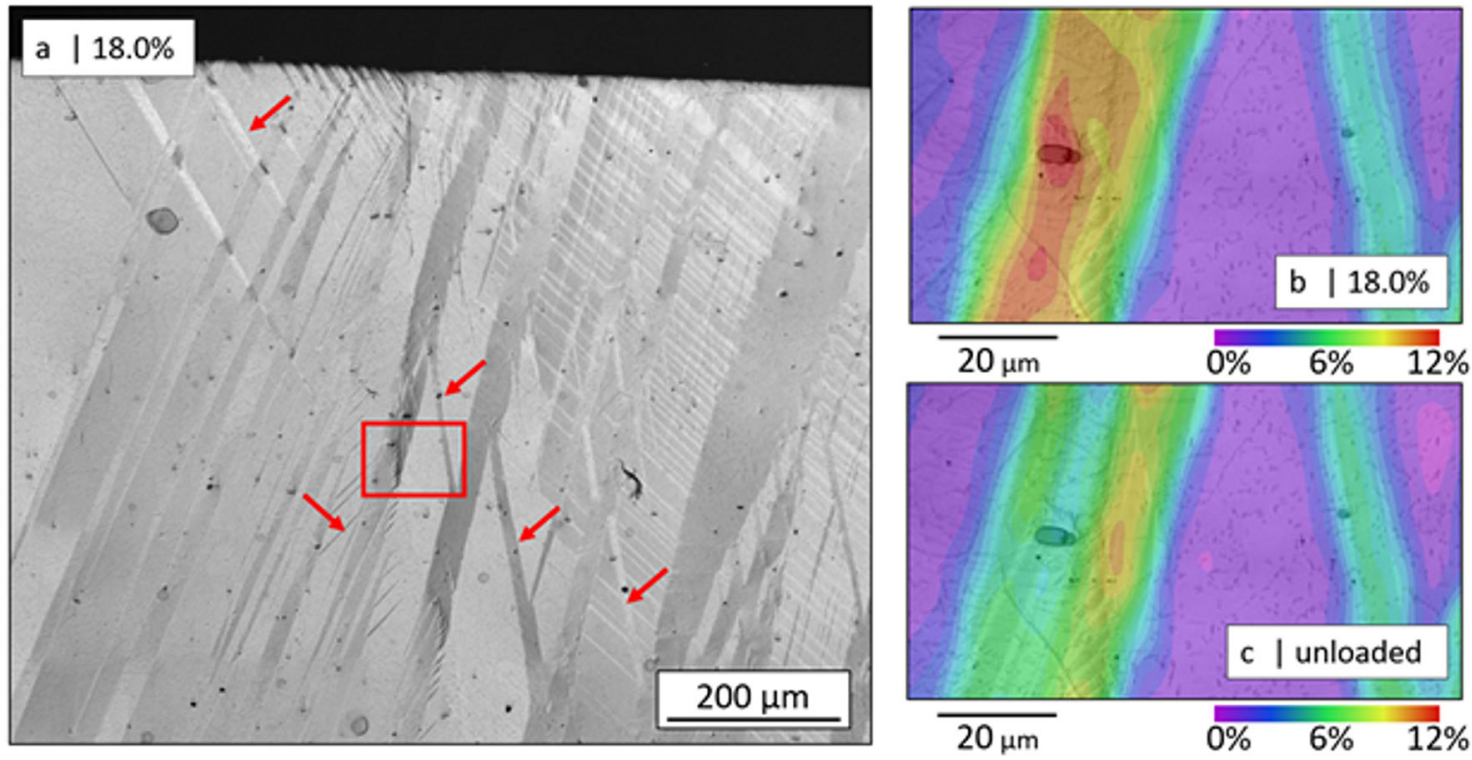

Fig. 6 CLSM detail image and evaluation of the local strain distribution at the grain boundary. Detail image (a) of the area marked in Fig. 5a with a white box. Local strain distribution in LD at $18 \%$ applied strain (b) and after unloading (c) of the area marked in (a) with a red box. Red arrows in (a) highlight additional martensite plates being characterized by deviating orientations (Color figure online)

previous sample, this sample is characterized by a superior reversibility.

Figure 8a reveals that the left grain transforms first. After initial severe transformation within the grain boundary area a locally stable condition is reached, i.e., no further changes are seen here. Afterwards, a new martensite plate appears within the right grain upon further loading (black arrow). Despite the high misorientation between the grains, again martensite plates can be identified, which seem to cross the grain boundary partially without a change of orientation. Still, after unloading both grains are characterized by a high reversibility of transformation (Fig. 8b). This is in good agreement with the stress-strain hysteresis shown in Fig. 7c.

A CLSM image detailing the grain boundary area in the loaded state is shown in Fig. 9a. It can be seen that stress concentrations at the upper part of the grain boundary are accommodated by martensite plates with different orientations. This is likely caused by the grain boundary morphology leading to stress states known from grain boundary
Fig. 7 Superelastic behavior of the $\mathrm{Fe}-\mathrm{Mn}-\mathrm{Al}-\mathrm{Ni}$ tensile sample with a misorientation angle of $60^{\circ}$ between the transforming grains. EBSD orientation mapping plotted for LD (a). The area considered for in situ characterization is marked with a white box. The corresponding $\langle 001\rangle$ pole figure highlighting the involved grains is shown in (b) besides the stress-strain curve up to $5.5 \%$ applied strain in (c)

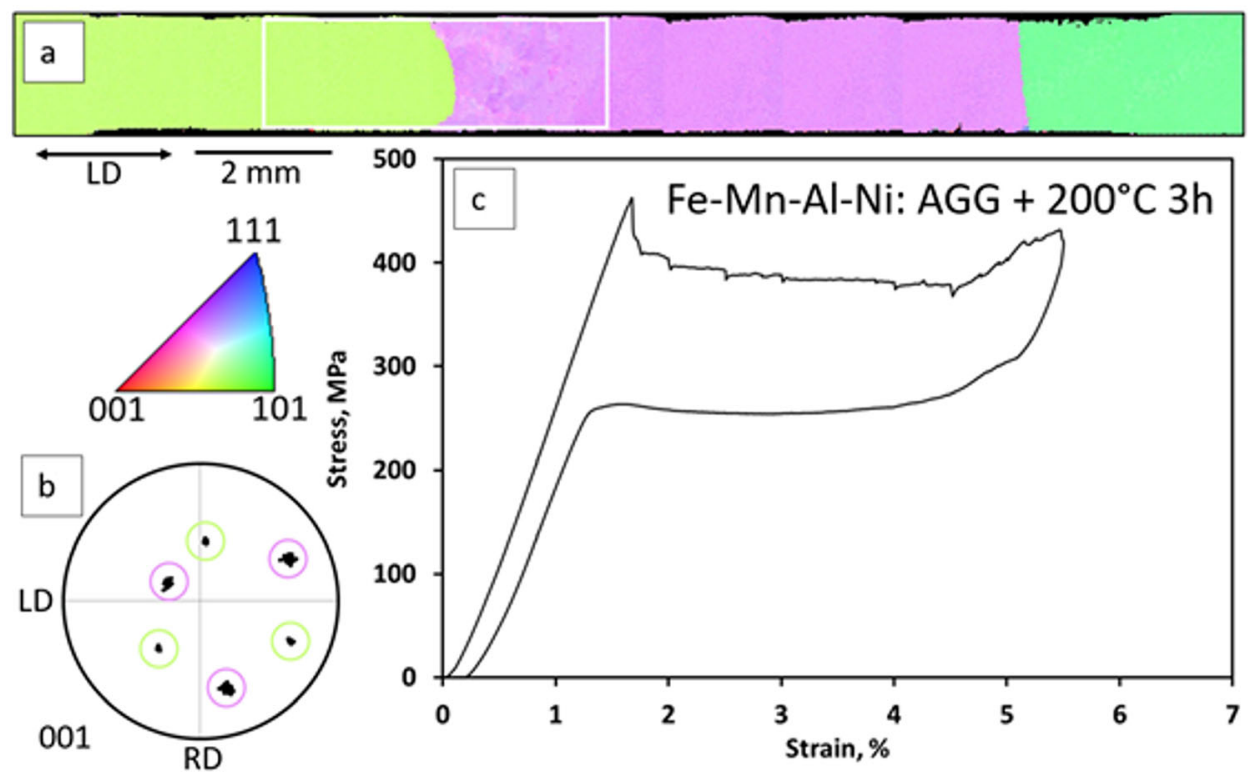




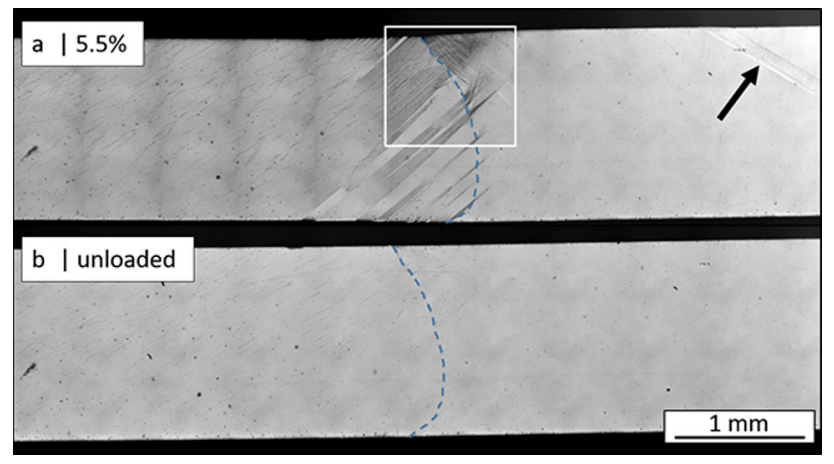

Fig. 8 In situ characterization of the sample shown in Fig. 7a. CLSM overview images at 5.5\% applied strain (a) and after unloading (b). The white box in (a) marks the area shown in Fig. 9a in detail. Grain boundaries are indicated by blue dashed lines. The black arrow points at a martensite plate in the secondly activated grain (Color figure online)

triple points [35, 39]. In contrast, the martensite plates in the grain center run across the grain boundary and expand up to $400 \mu \mathrm{m}$ into the right grain. However, the magnified view in Fig. 9b reveals that the interaction at the grain boundary is accompanied by strong distortions and the formation of additional martensite plates with different orientations. Due to the high misorientation between the grains it had to be expected that unfavorable martensite will occur to accommodate the internal stresses. Figure 9c shows the local strain distribution after unloading in this region. It can be seen that the transformation in the left grain is completely reversible, whereas high residual strains remain in the martensitically transformed region in the right grain. Thus, the grain boundaries represent potential starting points for functional and structural fatigue in oligocrystalline structures. Advantageously, after reaching a locally stable condition, a sequential transformation within the grains sets in preventing further detrimental deformation within the grain boundary area.

\section{Conclusions}

In the present study, high resolution in situ tensile tests using CLSM supported by DIC were conducted to investigate the influence of grain orientations and grain boundaries with different misorientation angles on the martensitic transformation in oligocrystalline $\mathrm{Fe}-\mathrm{Mn}-\mathrm{Al}-\mathrm{Ni}$. By direct comparison of the experimentally determined local strains with theoretical transformation strains available in literature, it was possible to determine the martensite structure locally being present, i.e., twinned or detwinned. Eventually, this allowed to correlate the martensite structure and reversibility of transformation within grains of different orientation and in direct vicinity of grain boundaries. Based on the results reported in present work, the following conclusions can be drawn:

- Superelastic loading in near- $\langle 001\rangle$ orientation is accompanied by local detwinning of martensite within previous transformed areas within a single grain. During unloading the initially twinned martensite shows good reversibility, whereas the detwinned areas show almost no reversibility. In contrast, the near- $\langle 101\rangle$ orientation shows hardly any detwinning and, thus, a superior superelastic behavior. In consequence, hampering detwinning of previously twinned martensite seems to be the key to improve the reversibility of specific orientations such as $\langle 001\rangle$, which are currently prone to detwinning.

- Independent of the misorientation between the grains in oligocrystalline $\mathrm{Fe}-\mathrm{Mn}-\mathrm{Al}-\mathrm{Ni}$, stress concentrations locally occur at the grain boundaries leading to the formation of unfavored martensite in direct vicinity of the grain boundaries. In particular, if martensite plates cross the grain boundary, stress concentrations lead to the formation of irreversible martensite of unfavorable
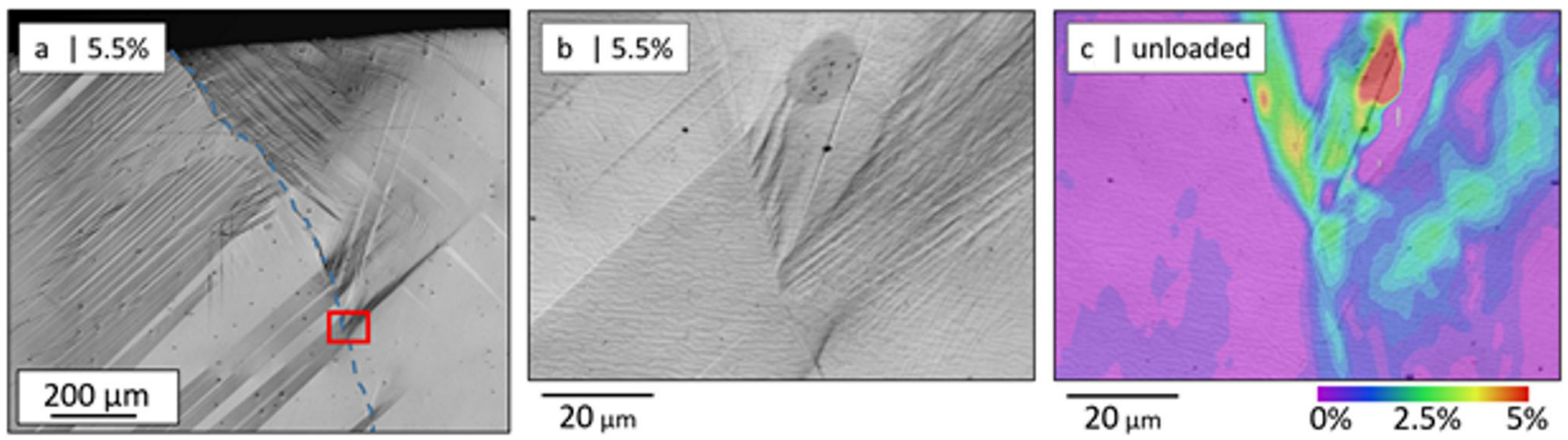

Fig. 9 CLSM detail image and evaluation of the local strain distribution at the grain boundary. Detail image (a) of the area marked in Fig. 8a with a white box. CLSM detail image (b) of the area marked in (a) with a red box. Local strain distribution after unloading of the corresponding area (c) (Color figure online) 
orientation. However, when a locally stable condition is established at the grain boundary, further transformation takes place preferentially within the newly activated grain preventing further detrimental deformation within the grain boundary area.

- Assessing the overall performance of Fe-Mn-Al-Ni SMA, the grain orientation-dependent reversibility predominates the local irreversibility at the grain boundary.

Acknowledgements Financial support by Deutsche Forschungsgemeinschaft (project number 400008732) is gratefully acknowledged.

Author Contributions AB: Conceptualization, Investigation, Visualization, Writing-Original draft preparation. MV: Conceptualization, Investigation, Visualization, Writing-Review \& Editing. TN: Writing-Review \& Editing, Supervision, Funding acquisition.

Funding Open Access funding enabled and organized by Projekt DEAL.

Open Access This article is licensed under a Creative Commons Attribution 4.0 International License, which permits use, sharing, adaptation, distribution and reproduction in any medium or format, as long as you give appropriate credit to the original author(s) and the source, provide a link to the Creative Commons licence, and indicate if changes were made. The images or other third party material in this article are included in the article's Creative Commons licence, unless indicated otherwise in a credit line to the material. If material is not included in the article's Creative Commons licence and your intended use is not permitted by statutory regulation or exceeds the permitted use, you will need to obtain permission directly from the copyright holder. To view a copy of this licence, visit http://creativecommons. org/licenses/by/4.0/.

\section{References}

1. Wayman CM, Ōtsuka K (1999) Shape memory materials, 1st edn. Cambridge University Press, Cambridge

2. Mohd Jani J, Leary M, Subic A et al (2014) A review of shape memory alloy research, applications and opportunities. Mater Des 56:1078-1113. https://doi.org/10.1016/j.matdes.2013.11.084

3. Kaya E, Kaya I (2019) A review on machining of NiTi shape memory alloys: the process and post process perspective. Int $\mathbf{J}$ Adv Manuf Technol 100:2045-2087. https://doi.org/10.1007/ s00170-018-2818-8

4. Cladera A, Weber B, Leinenbach C et al (2014) Iron-based shape memory alloys for civil engineering structures: an overview. Constr Build Mater 63:281-293. https://doi.org/10.1016/j.con buildmat.2014.04.032

5. Tanaka Y, Himuro Y, Kainuma R et al (2010) Ferrous polycrystalline shape-memory alloy showing huge superelasticity. Science 327:1488-1490. https://doi.org/10.1126/science.1183169

6. Sawaguchi T, Maruyama T, Otsuka H et al (2016) Design concept and applications of $\mathrm{Fe}-\mathrm{Mn}-\mathrm{Si}$-based alloys-from shapememory to seismic response control. Mater Trans 57:283-293. https://doi.org/10.2320/matertrans.MB201510

7. Leinenbach C, Kramer H, Bernhard C et al (2012) Thermo-mechanical properties of an $\mathrm{Fe}-\mathrm{Mn}-\mathrm{Si}-\mathrm{Cr}-\mathrm{Ni}-\mathrm{VC}$ shape memory alloy with low transformation temperature. Adv Eng Mater 14:62-67. https://doi.org/10.1002/adem.201100129
8. Janke L (2005) Applications of shape memory alloys in civil engineering structures-overview, limits and new ideas. Mater Struct 38:578-592. https://doi.org/10.1617/14323

9. Vollmer M, Krooß P, Karaman I et al (2017) On the effect of titanium on quenching sensitivity and pseudoelastic response in Fe-Mn-Al-Ni-base shape memory alloy. Scripta Mater 126:20-23. https://doi.org/10.1016/j.scriptamat.2016.08.002

10. Vollmer M, Arold T, Kriegel MJ et al (2019) Promoting abnormal grain growth in Fe-based shape memory alloys through compositional adjustments. Nat Commun 10:1. https://doi.org/10. 1038/s41467-019-10308-8

11. Omori T, Ando K, Okano M et al (2011) Superelastic effect in polycrystalline ferrous alloys. Science 333:68-71. https://doi.org/ $10.1126 /$ science. 1202232

12. Xia J, Noguchi Y, Xu X et al (2020) Iron-based superelastic alloys with near-constant critical stress temperature dependence. Science 369:855-858. https://doi.org/10.1126/science.abc1590

13. Vollmer M, Bauer A, Kriegel MJ et al (2021) Functionally graded structures realized based on $\mathrm{Fe}-\mathrm{Mn}-\mathrm{Al}-\mathrm{Ni}$ shape memory alloys. Scripta Mater 194:113619. https://doi.org/10.1016/j.scriptamat. 2020.10.057

14. Omori T, Nagasako M, Okano M et al (2012) Microstructure and martensitic transformation in the Fe-Mn-Al-Ni shape memory alloy with B2-type coherent fine particles. Appl Phys Lett 101:231907. https://doi.org/10.1063/1.4769375

15. Ando K, Omori T, Ohnuma I et al (2009) Ferromagnetic to weakmagnetic transition accompanied by bcc to fcc transformation in Fe-Mn-Al alloy. Appl Phys Lett 95:212504. https://doi.org/10. $1063 / 1.3266848$

16. Tseng LW, Ma J, Hornbuckle BC et al (2015) The effect of precipitates on the superelastic response of $\left[\begin{array}{lll}1 & 0 & 0\end{array}\right]$ oriented FeMnAlNi single crystals under compression. Acta Mater 97:234-244. https://doi.org/10.1016/j.actamat.2015.06.061

17. Ozcan H, Ma J, Karaman I et al (2018) Microstructural design considerations in Fe-Mn-Al-Ni shape memory alloy wires: effects of natural aging. Scripta Mater 142:153-157. https://doi.org/10. 1016/j.scriptamat.2017.07.033

18. Vollmer M, Kriegel MJ, Walnsch A et al (2019) On the microstructural and functional stability of Fe-Mn-Al-Ni at ambient and elevated temperatures. Scripta Mater 162:442-446. https://doi.org/10.1016/j.scriptamat.2018.12.008

19. Vollmer M, Kriegel MJ, Krooß P et al (2017) Cyclic degradation behavior of $\langle 001\rangle$-oriented $\mathrm{Fe}-\mathrm{Mn}-\mathrm{Al}-\mathrm{Ni}$ single crystals in tension. Shap Mem Superelast 3:335-346. https://doi.org/10. 1007/s40830-017-0117-0

20. Ball JM, James RD (1987) Fine phase mixtures as minimizers of energy. Arch Rational Mech Anal 100:13-52

21. Saburi T (1981) The shape memory effect and related phenomena. Solid Solid Phase Transf 1455-1479

22. Tseng LW, Ma J, Wang SJ et al (2016) Effects of crystallographic orientation on the superelastic response of FeMnAlNi single crystals. Scripta Mater 116:147-151. https://doi.org/10. 1016/j.scriptamat.2016.01.032

23. Tseng LW, Ma J, Wang SJ et al (2015) Superelastic response of a single crystalline FeMnAlNi shape memory alloy under tension and compression. Acta Mater 89:374-383. https://doi.org/10. 1016/j.actamat.2015.01.009

24. Tseng LW, Ma J, Chumlyakov YI et al (2019) Orientation dependence of superelasticity in FeMnAlNi single crystals under compression. Scripta Mater 166:48-52. https://doi.org/10.1016/j. scriptamat.2019.02.034

25. Ojha A, Sehitoglu H (2016) Transformation stress modeling in new Fe Mn Al Ni shape memory alloy. Int J Plast 86:93-111. https://doi.org/10.1016/j.ijplas.2016.08.003

26. Vallejos JM, Giordana MF, Sobrero CE et al (2020) Excellent pseudoelasticity of Al-rich $\mathrm{Fe}-33 \mathrm{Mn}-17 \mathrm{Al}-6 \mathrm{Ni}-0.15 \mathrm{C}$ (at $\%$ ) 
shape memory single crystals obtained without an aging conditioning stage. Scripta Mater 179:25-29. https://doi.org/10.1016/j. scriptamat.2019.12.038

27. Poklonov VV, Chumlyakov YI, Kireeva IV et al (2018) Superelastic response in $\langle 122\rangle$-oriented single crystals of FeMnAlNi shape memory alloy in tension and compression. Mater Lett 233:195-198. https://doi.org/10.1016/j.matlet.2018.09.015

28. Ozcan H, Ma J, Wang SJ et al (2017) Effects of cyclic heat treatment and aging on superelasticity in oligocrystalline Fe-MnAl-Ni shape memory alloy wires. Scripta Mater 134:66-70. https://doi.org/10.1016/j.scriptamat.2017.02.023

29. Vollmer M, Segel C, Krooß P et al (2015) On the effect of gamma phase formation on the pseudoelastic performance of polycrystalline $\mathrm{Fe}-\mathrm{Mn}-\mathrm{Al}-\mathrm{Ni}$ shape memory alloys. Scripta Mater 108:23-26. https://doi.org/10.1016/j.scriptamat.2015.06. 013

30. Vollmer M, Krooß P, Kriegel MJ et al (2016) Cyclic degradation in bamboo-like Fe-Mn-Al-Ni shape memory alloys-the role of grain orientation. Scripta Mater 114:156-160. https://doi.org/10. 1016/j.scriptamat.2015.12.007

31. Omori T, Okano M, Kainuma R (2013) Effect of grain size on superelasticity in Fe-Mn-Al-Ni shape memory alloy wire. APL Mater 1:32103. https://doi.org/10.1063/1.4820429

32. Abuzaid W, Wu Y, Sidharth R et al (2019) FeMnNiAl iron-based shape memory alloy: promises and challenges. Shap Mem Superelast 1:C4-199. https://doi.org/10.1007/s40830-019-002309

33. Sutou Y, Omori T, Kainuma R et al (2013) Grain size dependence of pseudoelasticity in polycrystalline $\mathrm{Cu}-\mathrm{Al}-\mathrm{Mn}$-based shape memory sheets. Acta Mater 61:3842-3850. https://doi.org/ 10.1016/j.actamat.2013.03.022

34. Ueland SM, Schuh CA (2013) Transition from many domain to single domain martensite morphology in small-scale shape memory alloys. Acta Mater 61:5618-5625. https://doi.org/10. 1016/j.actamat.2013.06.003

35. Ueland SM, Schuh CA (2013) Grain boundary and triple junction constraints during martensitic transformation in shape memory alloys. J Appl Phys 114:53503. https://doi.org/10.1063/1.4817170
36. Ueland SM, Schuh CA (2012) Superelasticity and fatigue in oligocrystalline shape memory alloy microwires. Acta Mater 60:282-292. https://doi.org/10.1016/j.actamat.2011.09.054

37. Ueland SM, Chen Y, Schuh CA (2012) Oligocrystalline shape memory alloys. Adv Funct Mater 22:2094-2099. https://doi.org/ 10.1002/adfm.201103019

38. Sutou Y, Omori T, Yamauchi K et al (2005) Effect of grain size and texture on pseudoelasticity in $\mathrm{Cu}-\mathrm{Al}-\mathrm{Mn}$-based shape memory wire. Acta Mater 53:4121-4133. https://doi.org/10.1016/ j.actamat.2005.05.013

39. Lauhoff C, Vollmer M, Krooß P et al (2018) Pathways towards grain boundary engineering for improved structural performance in polycrystalline Co-Ni-ga shape memory alloys. Shap Mem Superelast 378:2. https://doi.org/10.1007/s40830-018-00204-3

40. Vollmer M, Krooß P, Segel C et al (2015) Damage evolution in pseudoelastic polycrystalline $\mathrm{Co}-\mathrm{Ni}-\mathrm{Ga}$ high-temperature shape memory alloys. J Alloy Compd 633:288-295. https://doi.org/10. 1016/j.jallcom.2015.01.282

41. Tseng LW, Ma J, Vollmer M et al (2016) Effect of grain size on the superelastic response of a FeMnAlNi polycrystalline shape memory alloy. Scripta Mater 125:68-72. https://doi.org/10.1016/ j.scriptamat.2016.07.036

42. Omori T, Iwaizako H, Kainuma R (2016) Abnormal grain growth induced by cyclic heat treatment in Fe-Mn-Al-Ni superelastic alloy. Mater Des 101:263-269. https://doi.org/10.1016/j.matdes. 2016.04.011

43. Vollmer M, Baunack D, Janoschka D et al (2020) Induction Butt welding followed by abnormal grain growth: a promising route for joining of $\mathrm{Fe}-\mathrm{Mn}-\mathrm{Al}-\mathrm{Ni}$ tubes. Shap Mem Superelasticity 5:489. https://doi.org/10.1007/s40830-019-00261-2

44. Tseng LW (2015) Microstructure and superelastic response of iron-based shape memory alloys. Doctoral thesis, Texas A\&M University, College Station, Texas, USA

Publisher's Note Springer Nature remains neutral with regard to jurisdictional claims in published maps and institutional affiliations. 